2020, Volume 10, International Conference Globalization, Innovation and Development. Trends and Prospects (G.I.D.T.P.), pages: 214-220 |

https://doi.org/10.18662/lumproc/gidtp2018/24

\section{Emotional Intelligence - A Condition of Managerial Success}

\section{Ionica-Luminiţa STOENICĂ ${ }^{1}$}

${ }^{1}$ Doctoral School of Economics and Humanities, Management, "Valahia" University of Targoviste, Romania, luminitastoenica@yahoo.com
Abstract: Emotional intelligence is nowadays an essential attribute of any efficient manager who is concerned about achieving great results and being successful in his career and life. One can state, according to experts in the area, that successoriented management begins with the manager's inner life management, which is a difficult task. Before leading others, one must be able to analyze oneself, understand oneself and control one's own feelings and emotions, also to empathize and develop constructive relationships in order to get oriented towards one's goals and towards success. So that an institution should make progress, it is essential for the manager to create a working climate meant to provide the staff with a positive state, full of confidence and optimism, honesty and comfort. A successful manager is characterized by flexibility, adaptability to diverse situations and a positive mood, which enhances the employees' achievements. Therefore, creating a healthy positive climate involves activating the components of both the manager's and the employees' emotional intelligence. Good self-knowledge helps managers organize themselves better, be more emphatic and coordinate their employees' activity more efficiently towards professional performance, acting optimistically, enthusiastically, persuasively and firmly in order to achieve the objectives. They are motivated for reaching the highest results, for accomplishing their aims and thus they mobilize their positive emotions for this purpose. Developed emotional intelligence, with all its components, represents an asset, providing extra credibility and being at the same time a condition for a top manager who acts efficiently in a well-functioning organizational background.

Keywords: competencies; emotional intelligence; management; manager; performance.

How to cite: Stoenică, I.-L. (2020). Emotional Intelligence A Condition of Managerial Success. In I. Panagoreț \& G. Gorghiu (vol. ed.), Lumen Proceedings: Vol. 10. International Conference Globalization, Innovation and Development. Trends and Prospects (G.I.D.T.P.) (pp. 214-220). Iasi, Romania: LUMEN Publishing House.

https://doi.org/10.18662/lumproc/gidtp2018/24 
Emotional intelligence, a concept so often used today, is an essential attribute of any efficient manager, concerned with performance and success in career and life. If in the past the emotions were irrelevant to the organizational environment, today attention is paid to their consequences upon the activity, the management based on emotional intelligence, able to channel the employees in the optimal direction.

Emotions keep people together within a team, an organization, and the effectiveness with which the manager deals with these emotions in order to achieve performance depends on his emotional intelligence level.

Emotional intelligence refers to the ability of identifying, understanding and managing emotions and feelings, of acting effectively within human relationships. It is, as psychologist and writer Daniel Goleman said, "the wisdom which we live our emotions with" [1].

For the good work of an institution, it is essential that the manager should create a space for the staff to have a positive, trustworthy and optimistic state, full of honesty and comfort at their workplace, so that people should be able to cooperate and do their best.

It can be said, according to Daniel Goleman's vision, that performance-oriented management starts with the management of the manager's inner life because, before guiding others, he needs to know how to analyze, understand and control his own states and emotions.

In the book "What It Means to Be a Good Leader," D. Goleman claims that, as a result of his research, he found that "among all the factors that affect performance, the leader's state of mind and behaviour are of surprising importance" [3], with a significant impact on performance, influencing emotional states and employee behaviours. A manager who possesses high emotional intelligence creates an atmosphere in which the exchange of information, the opening to new, the passion for work and enthusiasm are constantly developing, while a manager with a low emotional intelligence may establish a toxic climate, dominated by fear, uncertainty and anxiety.

Research carried-out by Alice Isen has highlighted, Goleman argues, that " a working environment characterised by good mood favours intellectual efficiency, makes people [....] apply the rules of the decision-making process in complex problems" [3].

In order to solve the problems he faces in an efficient way and to behave intelligently in interhuman relationships, a modern manager has to possess the key skill called emotional intelligence.

A successful manager easily adapts himself to various situations and has a positive mood, which increases the employees' performances. Achieving effective communication and a healthy workplace climate 
therefore requires the use of the emotional intelligence components of both the manager and the employees.

\section{Elements of the Emotional Intelligence that facilitate managerial communication towards success}

It can be said that communication is the vital center of activities within an organization. The managers' communication competences are indispensable to their role, as they are management acts necessary to the efficient functioning of the organization. These are proven during the meetings they lead, while animating the groups, coordinating the teams, in various direct interactions they have with their subordinates. The managers must prove that they are able to listen to the subordinates before taking decisions, that they have persuasion skills by means of dialogue, that they can communicate in a language accessible to the employees and allocate time for talking to them.

Emotional intelligence, with all its components, represents an asset and an important condition to achieve an efficient managerial communication in a performant organizationl framework.

In the pattern proposed by D. Goleman for the emotional intelligence, there are five components, which intertwine and synergistically interconnect for optimal development: Self-knowledge, Self-control, Selfmotivation, Empathy, Relationship management.

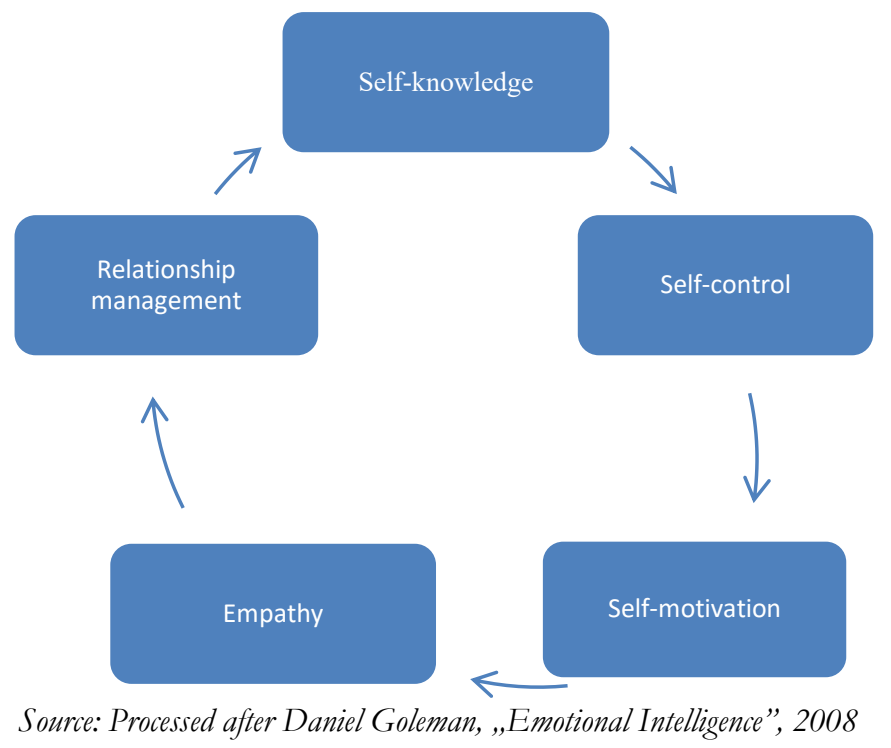

Figure 1. Emotional Intelligence components: 
1. Self-knowledge is the first step towards acquiring emotional intelligence and refers to good knowledge of personal emotions, through self-observation, as well as to recognizing a feeling when it appears and represents ,the foundation stone of the emotional intelligence" [2].

This basic component of emotional intelligence gives the manager the ability to deeply understand emotions, to know his strengths and weaknesses, his personal needs and desires, to have a clear vision of personal goals. Efficient managers make use of this capacity to precisely adjust their emotional states and realize at the same time the way their decisions influence others, as well as at what qualitative level their activity rises. They are confident, have the sense of reality, know which challenges and tasks to take over and complete, depending on the resources they have.

Managers who have good self-knowledge from an emotional point of view understand the way their feelings and emotions influence their performances. They are honest and inspire trust. They are capable of proper self-evaluation, they are attentive to the physical sensations and symptoms which might dominate them, they appreciate their values and capabilities correctly, knowing their limits and strengths. They have high self-esteem and are constantly interested in feedback in order to improve their activity.

2. Self-control represents another important ability which must characterize the attitude of a manager. This capacity offers the tendency towards reflection, the ability to master emotions, to keep them under control, to understand the others' too and act with probity, with transparency in order to be a real support for others. The managers who bear these qualities are optimistic, receptive to change, they are enterprising, easily adapt to new situations and create an atmosphere of trust. Having control over their own feelings and impulses, they generate a positive atmosphere, a good working environment, full of trust and comfort. They are able to stay calm and keep their good mood and self-control, even in tense situations or in competitive conditions and they do not allow emotions to control their behaviour. They direct the working group with transparency, accept challenges, calmly and skillfully approach difficult situations, act and guide for improving performance. They have the initiative, showing willingness to take advantage of opportunities.

The smart management of personal emotions also favours interpersonal relationships, professional relationships, self-empowerment, conflict resolution and even stress reduction. Emotional intelligence allows the manager to select feelings whose display can be useful and choose the most appropriate way to express them. 
3. Self-motivation, another component of emotional intelligence, is a characteristic feature of performing managers which allows the mobilization of positive emotions to achieve their goals in order to succeed. It is related to the desire to pursue and achieve the goals with energy and tenacity. Self-motivation depends on some emotional features, such as enthusiasm and perseverance in the face of obstacles to achieving the proposed goal. The ability to postpone the reward, to repress the impulse in favor of purpose is the essence of emotional self-control. These people are generally very energetic, being animated by the desire to achieve things and achieve their goals. They like challenges, they are eager for new approaches and proud of their successes. They remain optimistic even when faced with failure. Perseverance characterizes them and they seek solutions to face obstacles and achieve success. An optimistic, positive-minded person is likely to overcome himself to achieve the goals.

Goleman argues that "optimism, like hope, is a waiting horizon that, in general, things are ultimately resolved in life despite obstacles and frustrations" [2].

Optimistic managers know how to cope with failures and consider them to be beneficial experiences, from which they can learn and help them in personal and professional development.

4. Empathy is another capacity that is built, as D. Goleman says, on self-awareness, because the more we are opener to personal emotions, the more we are able to understand feelings, the emotional structure of others. Thus, empathic individuals are more attentive and show more interest in others, "being much more suited to charities that involve taking care of others, such as teachers, sales agents, or managers" [2]. They have the ability to listen, to observe the wishes of the subordinates, they easily capture aspects of body language, and grasp the different nuances of verbal and non-verbal expression. Empathic managers succeed in motivating and retaining their good employees and know how to provide useful feedback.

Empathy is undoubtedly one of the important qualities of a leader, a manager, enabling him to manage the relationships within a group, within an organization, to lead a team, to maintain an optimal level of communication. It is an important factor in keeping competent people in the institution, encouraging them and urging them to achieve performance in order to accomplish team cohesion and managerial success. It is essential for the manager to know his employees well, with their strengths and limits, to be concerned, to express interest and consideration in respect to them in order to capitalize on their talents and achieve the success of the team. He has to encourage people to engage in the activity, to take their feelings into account, to cooperate, to provide them with challenges and tasks according to their abilities and to make them self-indulgent in order to feel fulfilled. 
Therefore, in order for an organization to thrive, it is necessary for the manager to show interest in the employees and for them to feel that. $\mathrm{He}$ must appreciate well-done tasks, motivate people to overcome their limits and be competitive. This attitude leads to added credibility for the manager.

5. Relationship management is the fifth component of emotional intelligence and gives the manager more insight into the relationship with subordinates. According to Goleman's vision, this component involves inspired leadership (guidance and motivation using a convincing vision); influence (use of persuasion techniques); catalysing change (initiating relational management); conflict management (problem and disagreement solving), team spirit and collaboration (team building).

Goleman states that social skills allow managers to put their emotional intelligence to work.

They are aware of the importance of listening to their employees in order to better collaborate with them, at the same time realizing how their employees see them, the opinion they have about them. They build relationships based on trust with people in the organization, and trust is built on communication. The good manager knows that it is necessary to have a useful communication with employees, to send clear messages, to use effective persuasion strategies, to provide feedback on the activity that the subordinates perform.

Mark Horstman states that people feel that "the use of feedback will make them better when it is really needed." [4]. Managers push employees from their comfort zone and make them want more, motivate them to selfindulge in order to improve performance. They have the ability to mobilize members of the organization and succeed in achieving synergy of the group in order to achieve common goals.

The top manager has refined social skills and is capable of using an emotional or rational speech, depending on the situation. He knows how to adapt his behaviour according to the social context in which he is, to be in harmony with it, to act with tact, to use subtle non-verbal signals so that others should feel comfortable in his presence. He is concerned about good communication with the employees, about knowing social needs, he manifests emotional opening, spares enough time for this, envisaging good collaboration. He uses communication, direct interaction in the development of new reliable relationships. By communicating, managers are able to appreciate their employees, encourage them, get them involved, transmit them those values of the organization, and make them feel that they are an important part of it, so that the organization's goals should become their own goals. 


\section{Conclusions}

All these competences of the components of emotional intelligence are real assets of remarkable managers that enable them to make the right decisions, according to their values, to act with conviction and firmness in order to successfully accomplish the goals of the organization.

Emotional intelligence-driven leadership has a tremendous impact on employees and on the entire organization, channelling emotions in the right direction and coordinating the employees' work more effectively towards professional performance, success and excellence.

\section{References}

[1]. Goleman D, Boyatzis R, McKee A. Emotional Intelligence in Leadership. Bucharest: Curtea Veche Publishing House; 2007.

[2]. Goleman D. Emotional Intelligence. Bucharest: Curtea Veche Publishing House; 2008.

[3]. Goleman D. What it means to be a good leader. Why Emotional Intelligence is important. Bucharest: Curtea Veche Publishing House; 2017.

[4]. Horstman M. Effective manager. Bucharest: Curtea Veche Publishing House; 2017. 